\title{
Radical-Radical Recognition: Switchable Magnetic Properties and Re-entrant Behavior
}

\author{
Elisabeth M. Fatila, ${ }^{\dagger}$ R. Alex Mayo, ${ }^{\dagger}$ Mathieu Rouzières, ${ }^{\ddagger}, \diamond$ Michael C. Jennings, ${ }^{\S}$ Pierre \\ Dechambenoit, ${ }^{\ddagger} \diamond$ Dmitriy V. Soldatov, ${ }^{\dagger}$ Corine Mathonière, ${ }^{\Delta, f}$ Rodolphe Clérac, ${ }^{\ddagger, \diamond *}$ \\ Claude Coulon, ${ }^{\ddagger}, *$ and Kathryn E. Preuss ${ }^{\dagger *}$ \\ ${ }^{\dagger}$ Department of Chemistry, University of Guelph, Guelph, Ontario N1G 2W1, Canada \\ ${ }^{\ddagger}$ CNRS, CRPP, UPR 8641, F-33600 Pessac, France \\ 'University of Bordeaux, CRPP, UPR 8641, F-33600 Pessac, France \\ ${ }^{\S}$ FreeLance Crystallography, London, Ontario N6J 3J5, Canada \\ ${ }^{\triangle}$ CNRS, ICMCB, UPR 9048, F-33600 Pessac, France \\ 'University of Bordeaux, ICMCB, UPR 9048, F-33600 Pessac, France
}

\begin{abstract}
: $\pi-\pi$ radical interactions have exacting geometry requirements, significantly more stringent than those of a hydrogen bond or a van der Waals interaction. Here, supramolecular synthons based on such radical-radical recognition are employed to generate switchable structural and magnetic properties. Interactions between neighboring paramagnetic ligands of the $\mathrm{La}(\mathrm{hfac})_{3}(\mathrm{pyDTDA})_{2}$ coordination complex cause a rare re-entrant phase transition (hfac = 1,1,1,5,5,5-hexafluoroacetylacetonato-; pyDTDA = 4-(2'-pyridyl)-1,2,3,5-dithiadiazolyl). Below $100 \mathrm{~K}$, the complex is diamagnetic in the solid state, consistent with an $f^{0}$ lanthanum(III) ion and "pancake bonding" of the $\pi$-radical ligands. Upon heating, the supramolecular one-dimensional arrangement undergoes two sequential structural phase transitions, observed at ca. 160 and $310 \mathrm{~K}$, successively involving the rupture of half and then the totality of the "pancake bonds" and generating stepwise increases in the paramagnetic susceptibility. We use the structural and magnetic data to develop a theoretical model that clearly predicts the unprecedented re-entrant behavior of this radical-La(III)radical complex. Moreover, this microscopic free-energy model demonstrates that any system with essentially non-interacting "dimers" contains within itself the possibility of a distortion associated with re-entrant phase transitions if the lattice is "soft" enough (i.e., low rigidity).
\end{abstract}

\section{Introduction}

Many kinds of noncovalent (weak) interactions are known; however, it is often unclear how their specific features might be applied to achieve desirable materials properties. The directional dependence of hydrogen bonding, for example, has been employed to design supramolecular synthons with molecular self-recognition. ${ }^{1}$ Thus, the directionality of the hydrogen bond sets it apart from other weak interactions (e.g., van der Waals) and makes it useful in crystal engineering applications. $^{2}$ Related to this discussion is the concept of radical-radical interactions, or so-called "pancake bonding", 3,4 the use of which is currently gaining traction in the field of materials design. ${ }^{5-7}$ "Pancake bonding" between $\pi$-radicals is similar to hydrogen bonding in terms of bond strength ${ }^{8}$ and directional dependence. However, the extremely demanding geometry dependence of "pancake bonding" sets it apart from hydrogen bonding. "Pancake bonds" exhibit dependence upon precise alignment of the two interacting planar $\pi$-radicals, in terms of both rotational and in-plane displacement, or slippage. ${ }^{9}$ Small changes in the geometry have large effects on the strength of the "pancake bond". The question then arises, "Can the sensitivity of this geometry dependence be used to generate desirable properties?” While increasingly sophisticated applications of "pancake bonding" are emerging, ranging from supramolecular synthons ${ }^{10,11}$ to redox-switching in rotaxanes, ${ }^{12}$ the unique geometry dependence of the radicalradical interaction has yet to be fully exploited. Herein, we report a new molecule-based material that exhibits switchable magnetic properties resulting from a rare and counterintuitive sequence of phase transitions. The material's properties arise from the extreme sensitivity of the radical-radical "pancake bonds" to small changes in geometry. The results presented herein set the groundwork for establishing a new class of materials that employ the specific features of "pancake bonds" as highly sensitive molecular recognition elements. 
We report a re-entrant phase transition in a crystalline $\mathrm{La}(\mathrm{hfac})_{3}(\text { pyDTDA })_{2}$ molecular material (Figure 1), manifested as a change from a monoclinic space group $(C 2 / c)$ to triclinic $(P-1)$ and back to monoclinic $(C 2 / c)$, upon increasing temperature (hfac $=1,1,1,5,5,5-$ hexafluoroacetylacetonato-; pyDTDA = 4-(2'-pyridyl)-1,2,3,5dithiadiazolyl). At a molecular level, these phase transitions involve the rupturing, or "opening", of so-called "pancake bonds" $13-15$ between $\pi$-dimers of neighboring pyDTDA radical ligands, which is itself very unusual. As a result, the phase transitions also manifest as stepwise increases in the magnetic moment as the structure transitions from "closed", diamagnetic $[\mathrm{pyDTDA}]_{2}$ dimers to “open”, paramagnetic $[\mathrm{pyDTDA}]_{2}$ pairs. Because "pancake bonds" are a very common radical-radical interaction, it is important to determine why, in this specific material, rupturing of the "pancake bonds" occurs at all. A microscopic free energy model, developed using competing elastic and magnetic terms, is presented. The model demonstrates how an array of essentially independent dimers will undergo such a distortion if the lattice is "soft" enough (i.e., low rigidity). Furthermore, this general model explicitly predicts the observed re-entrant phase behavior.
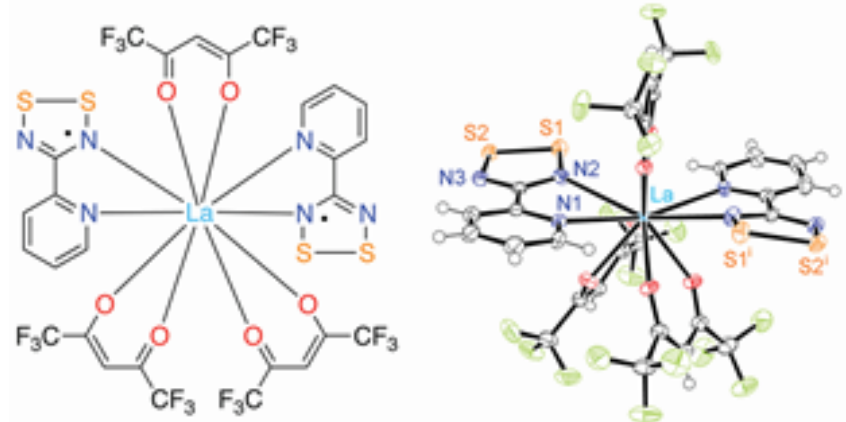

Figure 1. Line drawing and molecular structure of $\mathrm{La}(\mathrm{hfac})_{3}(\text { pyDTDA })_{2}$ in the low-temperature monoclinic phase at $100 \mathrm{~K}$; thermal ellipsoids drawn at $50 \%$ probability; symmetry code: (i) $1-x, y, 1 / 2-z$.

\section{Experimental Section}

\section{Synthesis}

General Considerations. Syntheses and manipulations were performed under an argon atmosphere using a glovebox and standard Schlenk techniques. Dried and degassed solvents were obtained from an LC Solvent Purification System (SPS) using dry packed columns containing $3 \AA$ molecular sieves and solvent kegs filled off-site by the manufacturer. Reagents were used as received. $\mathrm{La}(\mathrm{hfac})_{3}(\mathrm{DME})_{2}$ and pyDTDA were prepared according to literature procedure. ${ }^{16-18}$ Sublimations were carried out on a multistage programmable temperature tube furnace. IR spectra of pressed $\mathrm{KBr}$ pellets were collected using a Nicolet 510-FTIR spectrometer at ambient temperature. Elemental analyses were performed by MHW Laboratories, Phoenix, AZ, USA.

Synthesis of La(hfac) $)_{3}(\text { pyDTDA) })_{2}$. Anhydrous $\mathrm{CH}_{2} \mathrm{Cl}_{2}(20$ $\mathrm{mL})$ was added to a solid mixture of $\mathrm{La}(\mathrm{hfac})_{3}(\mathrm{DME})_{2}(0.2337$ g, $0.2485 \mathrm{mmol}$ ) and pyDTDA (0.1002 g, $0.5498 \mathrm{mmol})$ under argon. The red-purple solution was stirred for $1 \mathrm{~h}$. The solvent was removed under reduced pressure to afford a dark purple, shiny solid. Sublimation of the crude product at $105^{\circ} \mathrm{C}(378$
$\mathrm{K} ; 10^{-5}$ Torr dynamic vacuum) yielded a dark purple microcrystalline product; yield $0.1025 \mathrm{~g}$ (37\%). IR (KBr): 2959(vw), 1652(ms), 1599(w), 1554(mw), 1528(mw), 1501(m, br), 1385(w), 1257(s), 1205(s), 1147(s), 1095(m), 1053(w), 1010(vw), 947(vw), 916(vw), 832(mw), 792(mw), 747(vw), 740(vw), 660(ms), 632(w), 583(m), 518(w, br), 456(vw) $\mathrm{cm}^{-1}$. Anal. Calcd. for $\mathrm{LaC}_{27} \mathrm{H}_{11} \mathrm{~N}_{6} \mathrm{O}_{6} \mathrm{~S}_{4} \mathrm{~F}_{18}$ : C, 28.84; H, 0.99; N, 7.47\%. Found: C, 28.93; H, 1.00; N, 7.52\%. Single crystals suitable for X-ray diffraction were prepared by resublimation in a sealed tube under static pressure of $10^{-2}$ Torr.

Crystallographic Measurements. X-ray diffraction data were collected on single crystals of $\mathrm{La}(\mathrm{hfac})_{3}(\text { pyDTDA })_{2}$ at both Bordeaux and Guelph. At Bordeaux, the crystallographic data were collected with a Bruker APEX II Quasar diffractometer, equipped with an Oxford Cryostream 700plus cryostat and an Incoatec microfocus sealed-tube of monochromatized $\mathrm{MoK}_{\alpha}$ radiation. A single crystal was coated in Voltalef 90 grease, mounted on a fiber loop (for the crystal structure collected at $340 \mathrm{~K}$ ) or in a sealed glass capillary, and centered in the beam under a nitrogen flux. The program SAINT $^{19}$ was used to integrate the data, which was thereafter corrected using SADABS. ${ }^{20}$ The structure was solved using SHELXS-97 and refined by a full-matrix least-squares method on $F^{2}$ using SHELXL-97. ${ }^{21}$ All non-hydrogen atoms were refined with anisotropic displacement parameters. Hydrogen atoms were placed at calculated positions using suitable riding models. At Guelph, the data were collected on a SuperNova Agilent single-crystal diffractometer with Atlas CCD detector, equipped with a CryoJet XL low-temperature device and a microfocus $\mathrm{MoK}_{\alpha}$ radiation source. The data were processed using CrysAlisPro software. ${ }^{22}$

Magnetic Measurements. Magnetic measurements were performed on several polycrystalline samples of $\mathrm{La}(\mathrm{hfac})_{3}(\text { pyDTDA })_{2}$ ranging in mass from 6.1 to $17.9 \mathrm{mg}$. Samples were sealed under argon atmosphere in polyethylene bags $(3 \times 0.5 \times 0.02 \mathrm{~cm} ; 20-30 \mathrm{mg})$ in order to collect data in the temperature range of 1.8 to $330 \mathrm{~K}$ or in polypropylene bags $(3 \times 0.5 \times 0.02 \mathrm{~cm}$; $15-25 \mathrm{mg})$ in order to collect data up to $380 \mathrm{~K}$. Magnetic measurements were obtained with the use of a Quantum Design SQUID magnetometer MPMS-XL functioning between 1.8 and $400 \mathrm{~K}$ for direct-current (dc) applied fields ranging from -7 to $+7 \mathrm{~T}$. Prior to the experiments, the field-dependent magnetization was measured at $100 \mathrm{~K}$ on each sample in order to prove the absence of any bulk ferromagnetic impurities. All magnetic data were corrected for the sample holder and diamagnetic contributions.

\section{Results and Discussion}

\section{Brief Word on "Pancake Bonding" of DTDA Radicals}

Typical of many planar $\pi$-radicals, 4-R-1,2,3,5dithiadiazolyls (DTDAs) exhibit a propensity to assemble as "pancake bonded" $\pi$-dimers in the solid state. ${ }^{10,15,23,24}$ The $\pi$ dimers are usually diamagnetic below room temperature, ${ }^{25}$ especially when the substituent $\mathrm{R}$ is an electron donating group, although there are rare examples wherein thermal population of the triplet excited state is evident by EPR spectroscopy (typically when $\mathrm{R}$ is electron withdrawing). ${ }^{26}$ There are also examples of DTDA radicals that do not dimerize in the solid state (when $\mathrm{R}$ is electron withdrawing and provides steric bulk). ${ }^{27-30}$ From these observations, it can be surmised that there exists a range of dimerization enthalpies 
associated with "pancake bonding" between DTDA heterocycles and that the electron donating/withdrawing capacity of the $\mathrm{R}$ group is an important factor.
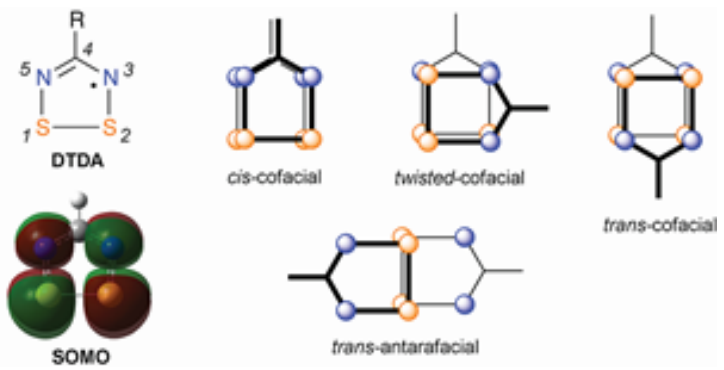

Figure 2. Line drawing of a generic 4-R-1,2,3,5-dithiadiazolyl (DTDA); surface of the singly occupied molecular orbital (SOMO) of 4-H-1,2,3,5-dithiadiazolyl generated using B3LYP/6$31 \mathrm{G}(\mathrm{d}, \mathrm{p})^{31}$ and rendered using isovalue $=0.0200 ;{ }^{32}$ line drawings of four common geometries for [DTDA $]_{2} \pi$-dimers.

When DTDAs form $\pi$-dimers, they typically do so in one of four structural motifs ${ }^{10}$ with very specific geometries. Inspection of the singly occupied molecular orbital (SOMO) of a generic DTDA radical, a $\pi^{*}$ orbital distributed over the heteroatoms and nodal at the $\mathrm{C}$ atom (Figure 2), helps to rationalize the geometry of these motifs. The cis-cofacial, twisted-cofacial, and trans-cofacial geometries are simply "pancake bonds" involving the $\sigma$ overlap of all four lobes of the SOMOs, rotated by roughly $0^{\circ}, 90^{\circ}$, and $180^{\circ}$ respectively, and consistent with the roughly square shape of the SOMO. ${ }^{14}$ The trans-antarafacial motif is the $\sigma$ overlap of only two lobes of the SOMO, those centered on the S atoms.

\section{Structural Features}

Single crystals of $\mathrm{La}(\mathrm{hfac})_{3}(\mathrm{pyDTDA})_{2}$ suitable for X-ray diffraction were obtained by double sublimation of the crude product at $105{ }^{\circ} \mathrm{C}$ under reduced pressure. The crystal structure of this complex undergoes two sequential phase changes, from monoclinic $(C 2 / \mathrm{c})$ to triclinic $(P-1)$ and back to monoclinic $(C 2 / \mathrm{c})$, upon increasing temperature. As expected in the case of phase transitions with a broken symmetry, ${ }^{33}$ the appearance of multiple crystalline domains (twinning) is systematically and reproducibly observed in the triclinic phase, whereas a perfect single-domain crystal is seen by $\mathrm{X}$ ray diffraction in the monoclinic phases.

At all temperatures, the $\mathrm{La}(\mathrm{hfac})_{3}(\mathrm{pyDTDA})_{2}$ moiety is a ten-coordinate complex of a diamagnetic $\left(f^{0}\right)$ lanthanum(III) ion. The pyDTDA ligands are $\mathrm{N}$-coordinated to $\mathrm{La}(\mathrm{III})$ in a bidentate fashion (Figure 1), similar to previously reported transition metal coordination complexes of this radical ligand. ${ }^{16-18}$ In both monoclinic phases (vide infra), the pyDTDA ligands are symmetry-related. Although the symmetry is lowered in the triclinic phase, the coordination geometry does not change dramatically as a function of temperature and, in all phases, it is best described as a sphenocorona, ${ }^{34}$ typical of 10 -coordinate lanthanide species. The thermally-induced structural changes have been tracked as a function of temperature by collecting X-ray diffraction data on a single crystal from 100 to $340 \mathrm{~K}$ (a total of 220 data collections).

The lowest temperature phase (Phase $\mathrm{I}_{\mathrm{LT}}$ ), below ca. $160 \mathrm{~K}$, is characterized by close contacts between the heterocycles of the pyDTDA ligands on neighboring molecules (Figure 3a). The radical ligands form [pyDTDA $]_{2}$ pairs in the so-called trans-cofacial motif ${ }^{10}$ with an inversion center located between neighboring DTDA planes. At $100 \mathrm{~K}$, the mean distance between the planes of the DTDA heterocycles is $\sim 3.2 \AA$, well within the sum of van der Waals radii for the constituent $\mathrm{N}$ and $\mathrm{S}$ atoms and consistent with the formation of diamagnetic $\pi$-dimers, via so-called "pancake bonding". ${ }^{13-15,35}$ The dimerization of the pyDTDA moieties serves to assemble the complexes into supramolecular chains propagating along the [001] direction (Figure 3a). Above ca. $160 \mathrm{~K}$, observation of the diffraction precession patterns (Figure 4) reveals the appearance of new reflections, which were forbidden by symmetry in the monoclinic $C 2$ /c space group (Figure $4 a)$. The appearance of these reflections (Figure 4b) is fully consistent with a lowering of symmetry from monoclinic to triclinic.
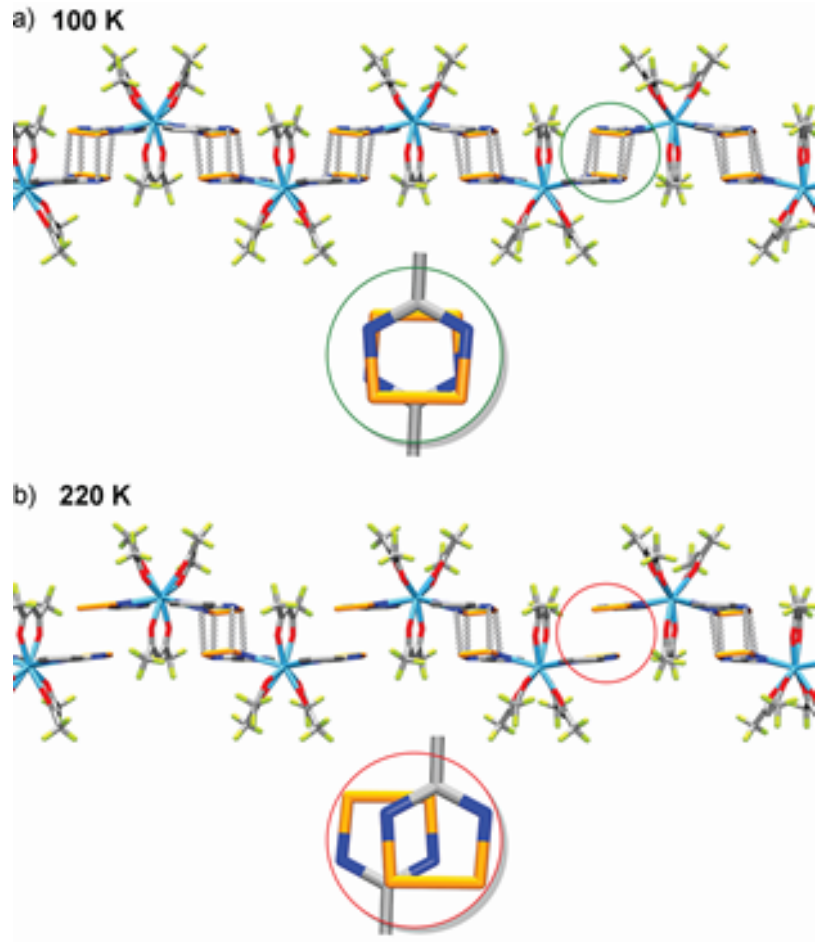

c) $340 \mathrm{~K}$

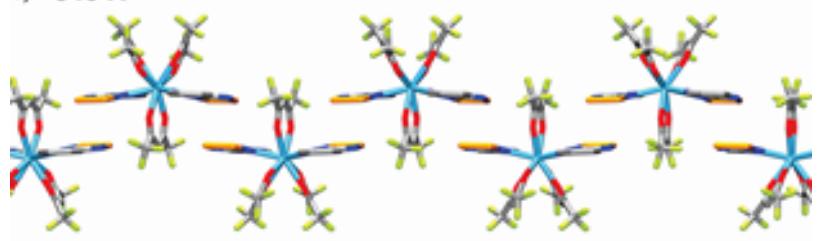

Figure 3. Excerpts from the crystal structures showing the supramolecular chains and highlighting the close contacts in the trans-cofacial dimerization of neighboring pyDTDA moieties: (a) Phase ILT at $T=100 \mathrm{~K}$, monoclinic (C2/c); (b) Phase II at $T=220$ $\mathrm{K}$, triclinic (P-1); (c) Phase $\mathrm{I}_{\mathrm{HT}}$ at $T=340 \mathrm{~K}$, monoclinic $(C 2 / \mathrm{c})$.

Between 160 and $310 \mathrm{~K}$, the triclinic $(P-1)$ phase (Phase II) shows the preservation of supramolecular chains of $\mathrm{La}(\mathrm{hfac})_{3}$ (pyDTDA) $)_{2}$ complexes (now propagating in [111] in $P-1$; Figure $3 b)$. In contrast with the monoclinic phase, half of the [pyDTDA $]_{2}$ dimers have "popped open", specifically every second pair is now "open". Each molecule now has one pyDTDA ligand participating in the formation of a "closed" 
("pancake bonded”) [pyDTDA $]_{2}$ dimer with a neighboring complex (mean distance between planes $\sim 3.2 \AA$ at $220 \mathrm{~K}$ ) and one pyDTDA ligand that is no longer engaged in pancake bonding and is part of an "open" [pyDTDA] $]_{2}$ pair (Figure 3b). While the "closed" dimers maintain the same trans-cofacial geometry as those described above, the "open” radical pairs are characterized by an increase in the interplanar distance between neighboring DTDA heterocycles accompanied by a lateral translation, or in-plane slippage of the heterocycles with respect to one another (Figure $3 b$ ). The shortest contacts between neighboring heterocycles of an "open" pair are between the $\mathrm{C}$ atom and an $\mathrm{S}$ atom of each DTDA (C...S, $3.413(7) \AA$ at $220 \mathrm{~K})$. Because the SOMO of a DTDA radical is nodal at the $C$ atom (Figure 2), the "open" [pyDTDA $]_{2}$ pairs no longer possess a geometry consistent with "pancake bonding". They are now positioned such that there is approximately orthogonal overlap between the two SOMOs.

At ca. $310 \mathrm{~K}$, the reflections associated with the triclinic phase (Figure 4b) disappear and the diffraction pattern observed below $160 \mathrm{~K}$ is recovered (Figures 4a, c). This observation is consistent with increased symmetry and a second phase transition from triclinic back to monoclinic (Figure 3c). The high-temperature monoclinic (C2/c) structure (Phase $\mathrm{I}_{\mathrm{HT}}$ ) is characterized by a return of the symmetry elements that relate all the pyDTDA ligands to one another. In this phase, all the $[\mathrm{pyDTDA}]_{2}$ dimers have been "opened" (Figure 3c) by in-plane slippage of the heterocycles, accompanied by an increase in intermolecular contact distances (C...S, 3.424(8) $\AA$ at $340 \mathrm{~K}$ ) comparable to those observed for the "open" pairs in the triclinic phase.

It is important to highlight that the rupturing of [pyDTDA $]_{2}$ dimers has never been observed before in the solid state. However, a small number of related 1,3,2-dithiazole radicals are known to exhibit structural phase transitions from diamagnetic $\pi$-dimers to undimerized paramagnetic monomers with large hysteresis. ${ }^{36-40}$ These phase transitions are either the result of significant "plate slippage" of molecular/crystallographic planes ${ }^{41}$ or of "tilting” of molecular planes in a "domino cascade". ${ }^{42-44}$ Thus, although there is precedent for solid-state monomer-dimer phase transitions in related thiazyl species, the actual structural changes are only marginally comparable.

Changes in the crystal packing of the supramolecular chains (Figure 5), consistent with the three-dimensional nature of the phase transition, are also observed as a function of temperature. The myriad of close contacts between chains is dominated by F...F interactions, which are unlikely to be particularly influential on the structure owing to the low polarizability of fluorine. In phase $\mathrm{I}_{\mathrm{LT}}$, there is also a short interchain contact between an hfac $\mathrm{F}$ atom and the pyridyl C-H ortho to $\mathrm{N} 1$ (F4...C1 $3.26 \AA$ at $100 \mathrm{~K}$ ). The C-F...H-C contacts are formed in a reciprocal manner such that there are two such contacts between the two relevant molecules in neighboring chains. These interchain contacts can be traced through the structure in [101] (Figure 5a). In Phase II, the reciprocal C-F...H-C contacts remain intact with one neighboring chain (F4...C1 $3.29 \AA$ at $220 \mathrm{~K}$ ) but are significantly lengthened with the other neighboring chain (F13...C22 $3.42 \AA$ at $220 \mathrm{~K}$ ). Only the pyDTDA ligand that is part of a "closed" [pyDTDA $]_{2}$ dimer (in the chain) maintains a close C-F...H-C contact between chains (Figure $5 b$ ). In phase $\mathrm{I}_{\mathrm{HT}}$, the distances between all interchain contacts have also increased, with F4...C1 achieving $3.47 \AA$ at $340 \mathrm{~K}$ (Figure $5 c)$. The ability of C-F to act as a hydrogen bond acceptor is still an ongoing debate, ${ }^{45-47}$ but the influence of the C-F...H-C contacts observed in the solid state structures of phases $\mathrm{I}_{\mathrm{LT}}$ and II for $\mathrm{La}(\mathrm{hfac})_{3}$ (pyDTDA) $)_{2}$ appears to be determinant in generating the observed phase transitions.

a) $100 \mathrm{~K}$

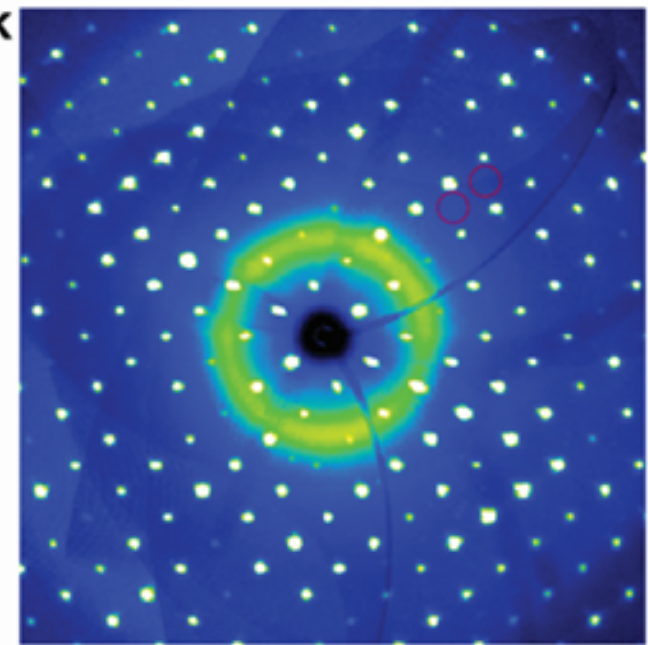

b) $220 \mathrm{~K}$

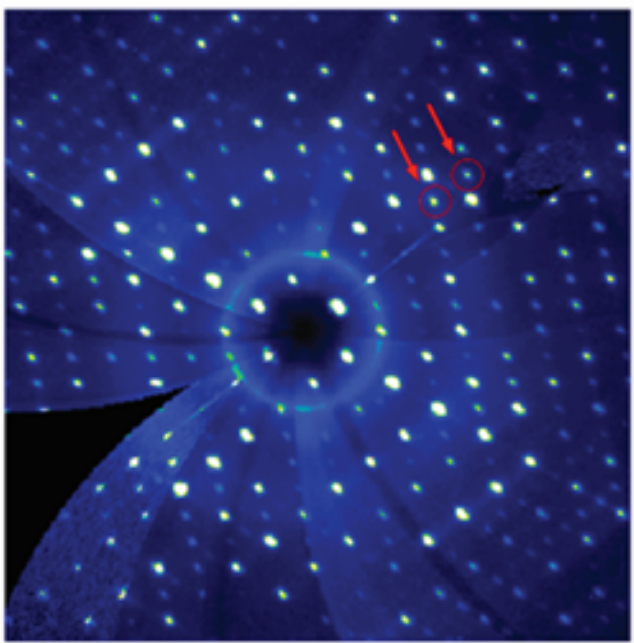

c) $340 \mathrm{~K}$

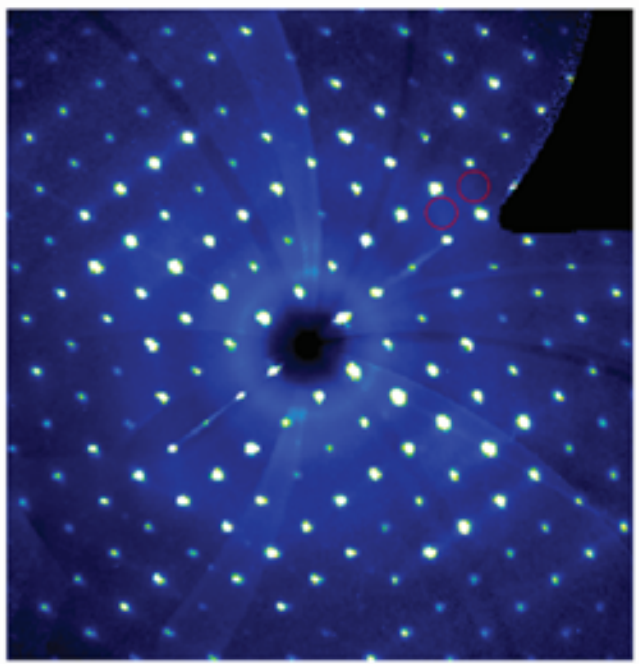

Figure 4. Reconstructed precession images of the $\{0 \mathrm{kl}\}$ plane (in the triclinic notation) at 100,220 , and $340 \mathrm{~K}$ showing the disappearance of reflections at low and high temperatures. (0 4 -5) 
and (0 5 -6) reflections for which the intensity was probed as a function of the temperature, are shown by the red circles and arrows. Data were collected on the same crystal at 220 and $340 \mathrm{~K}$, whereas another one was used at $100 \mathrm{~K}$.

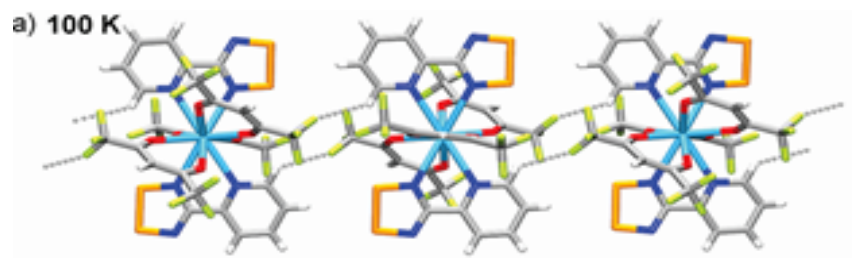

b)

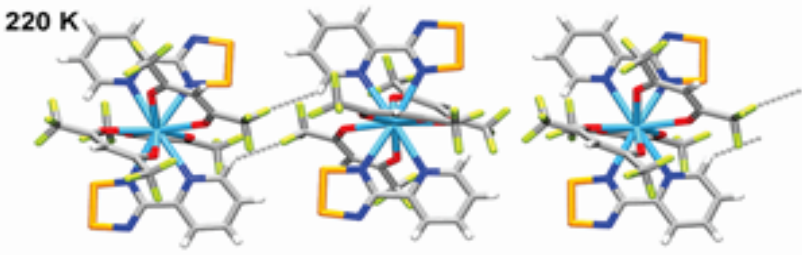

c) $340 \mathrm{~K}$

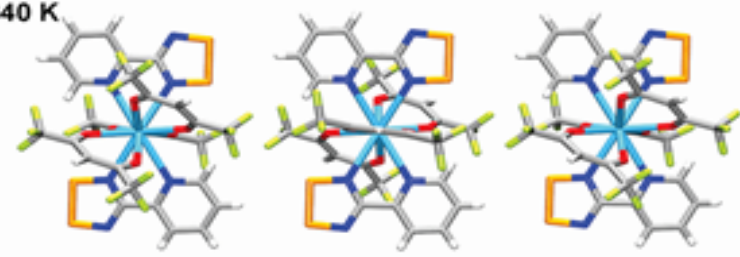

Figure 5. Close contacts between $\mathrm{F}$ and $\mathrm{H}$ atoms occur between chains at (a) $100 \mathrm{~K}$ (Phase $\mathrm{I}_{\mathrm{LT}}$ ) but are partially severed in (b) Phase II (shown at $220 \mathrm{~K}$ ) and completely severed in (c) Phase $\mathrm{I}_{\mathrm{HT}}$ (shown at $340 \mathrm{~K}$ ).

\section{Magnetic Properties}

The signature of the phase transitions in $\mathrm{La}(\mathrm{hfac})_{3}(\text { pyDTDA })_{2}$, observed by the X-ray diffraction technique (vide supra), was also studied by optical reflectivity and magnetic susceptibility measurements between 1.8 and $380 \mathrm{~K}$, as well as by differential scanning calorimetry (DSC). The optical (Figures S1 and S2 in the Supporting Information) and calorimetric (Figures S3 and S4) data are consistent with the phase transitions observed by structural and magnetic measurement (vide infra). Both are discussed in detail in the supporting information. The magnetic properties are described herein.

Below $80 \mathrm{~K}$, the value of the $\chi T$ product is very close to zero $\left(0.036 \mathrm{~cm}^{3} \mathrm{Kmol}^{-1}\right.$; Figure 6), suggesting that $\mathrm{La}(\mathrm{hfac})_{3}(\text { pyDTDA })_{2}$ is in a diamagnetic state, consistent with the formation of "closed" [pyDTDA $]_{2}$ dimers throughout the supramolecular chains. The residual paramagnetism likely originates from defects in the crystal structure and is a common magnetic feature of such $[\mathrm{DTDA}]_{2}$ dimers, ${ }^{48,49}$ and generally of materials with a singlet ground state. Above $80 \mathrm{~K}$, the $\chi T$ product increases rapidly with an inflection point at 163 $\mathrm{K}$ (see $d \chi T / d T$ versus $T$ in Figure 6 ) and, at $240 \mathrm{~K}$, reaches a value of $0.33 \mathrm{~cm}^{3} \mathrm{Kmol}^{-1}$ that corresponds well to one $S=1 / 2$ spin per molecule $\left(C=0.375 \mathrm{~cm}^{3} \mathrm{Kmol}^{-1}\right.$ for $\left.g=2\right)$. The magnetic properties and the sigmoidal-shape feature centered at $163 \mathrm{~K}$ are thus in agreement with the assessment of the crystallographic behavior, specifically that the phase transition from Phase $\mathrm{I}_{\mathrm{LT}}$ to Phase II ruptures half of the "closed" diamagnetic [pyDTDA $]_{2}$ dimers forming “open” paramagnetic $[\text { pyDTDA }]_{2}$ pairs.

As the temperature is increased above $240 \mathrm{~K}$, the $\chi T$ value increases rapidly with a second inflection point at ca. $312 \mathrm{~K}$ (Figure 6). The $\chi T$ value approaches $0.56 \mathrm{~cm}^{3} \mathrm{Kmol}^{-1}$ as the temperature approaches the sublimation temperature of $380 \mathrm{~K}$. These observations are consistent with the observed structural phase change wherein the remaining "closed" [pyDTDA $]_{2}$ dimers are ruptured ("opened") upon transitioning from Phase II to Phase $\mathrm{I}_{\mathrm{HT}}$. At a scan rate of $0.6 \mathrm{~K} / \mathrm{min}$, no conclusive evidence for thermally induced hysteresis was observed upon cycling the temperature.

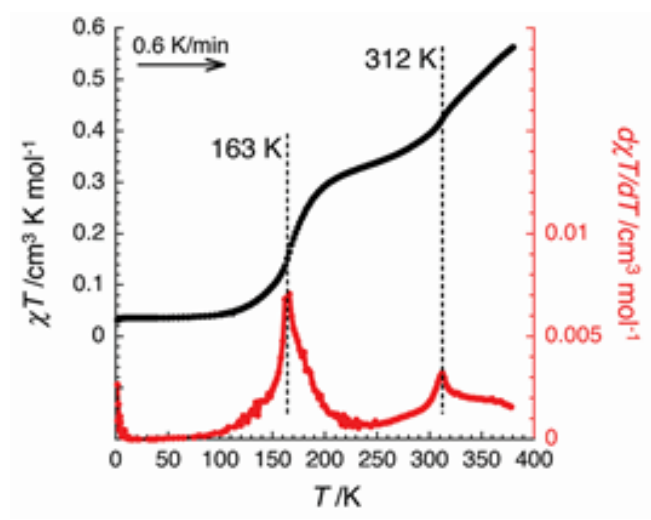

Figure 6. Temperature dependence of the $\chi T$ product and $\mathrm{d} \chi T / \mathrm{d} T$ derivative for $\mathrm{La}$ (hfac) 3 (pyDTDA) 2 at $0.1 \mathrm{~T}$ (with $\chi$ defined as the magnetic susceptibility equal to $M / H$ per mole of $\mathrm{La}(\mathrm{hfac})_{3}(\mathrm{pyDTDA})_{2}$ complex) at $0.6 \mathrm{~K} / \mathrm{min}$ (heating mode).

\section{Brief Word on Inverse Melting and Re-entrant Phase Transitions}

Inverse melting and re-entrant phase transitions are among the most interesting and unusual transition phenomena. In simple terms, inverse melting describes the (counterintuitive) transition from a solid to a liquid phase with decreasing temperature (at constant pressure). ${ }^{50}$ More generally, it defines a transition in which the symmetry of a system increases upon cooling. ${ }^{51}$ Re-entrant phase transitions are related phenomena that include an inverse melting transition. As the temperature of the system is increased monotonically, the phase changes from a higher symmetry Phase I to a lower symmetry Phase II and then back to the original higher symmetry Phase I. It is worth noting that Tammann's seminal work on melting, published in $1903,{ }^{52}$ explicitly predicts the possibility of inverse melting and re-entrant phase transitions.

Although re-entrant phase transitions are rare, they have been observed in a variety of unrelated systems including simple molecular crystals (notably malononitrile), ${ }^{53}$ liquid crystals, ${ }^{54}$ copolymer gels, ${ }^{55}$ multicomponent liquid mixtures, ${ }^{56}$ Bechgaard salts, ${ }^{57}$ granular and "dirty" superconductors, ${ }^{58,59}$ antiferromagnets, ${ }^{60} \mathrm{Fe}(\mathrm{II})$ spin-crossover complexes, ${ }^{61}$ selfassemblies of amphiphilic molecules, ${ }^{62}$ metals, ${ }^{63}$ and black holes. ${ }^{64}$ Efforts to model these and other re-entrant phase transitions include the successful application of Landau theory, ${ }^{65}$ a phenomenological model that is appropriate for second order or weakly first order phase transitions, ${ }^{66-68}$ as well as the use of a microscopic free energy model based on competing terms in the free energy. ${ }^{53}$ 


\section{Free Energy Model of the Re-entrant Phase Transition}

The space group of crystalline La(hfac) $)_{3}(\text { pyDTDA })_{2}$ changes from $C 2 / \mathrm{c}$ to $P-1$ and back to $C 2 / \mathrm{c}$ in two sequential phase transitions as the temperature is increased or decreased. The inevitable question is whether this phenomenon is a reentrant phase transition or not. Is the low temperature $C 2 / \mathrm{c}$ phase the same phase as the high temperature $C 2 / \mathrm{c}$ phase? The answer is not immediately obvious as there is a clear difference in the magnetic properties of these two phases. To answer the question regarding the assignment of the observed phenomena as evidence of a re-entrant phase transition, we analyzed the structural transition sequence for $\mathrm{La}(\mathrm{hfac})_{3}(\mathrm{pyDTDA})_{2}$ on the basis of combined magnetic and structural data, which have been modeled with a microscopic approach.

To develop a simple microscopic model to analyze the phase transitions, it should first be noted from the crystal structures (vide supra) that the translations of atoms occurring during both phase changes are small. This implies that a large term in the free energy, $F$, of the system determines the main structure and that the distortions generating the phase transition are governed by much smaller terms. This hypothesis is verified experimentally by measuring the unit cell parameters as a function of the temperature (considering 217 unit cells determined between 100 and $340 \mathrm{~K}$ ) and extracting the temperature dependence of the average distance between two $\mathrm{La}(\mathrm{hfac})_{3}(\text { pyDTDA })_{2}$ complexes (Figure 7 ), that is indeed the modulus of the $\overrightarrow{\boldsymbol{u}}=(\overrightarrow{\boldsymbol{a}}+\overrightarrow{\boldsymbol{b}}+\overrightarrow{\boldsymbol{c}}) / \mathbf{2}$ vector in the triclinic space group. ${ }^{69}$ As shown in Figure 7, no significant anomalies are observed at either phase transition, supporting the assumption that the mean structure is determined by a much larger free energy term than the distortion itself. It is then feasible to consider the mean structure as a constraint and to develop a perturbative microscopic model using only small free energy terms.

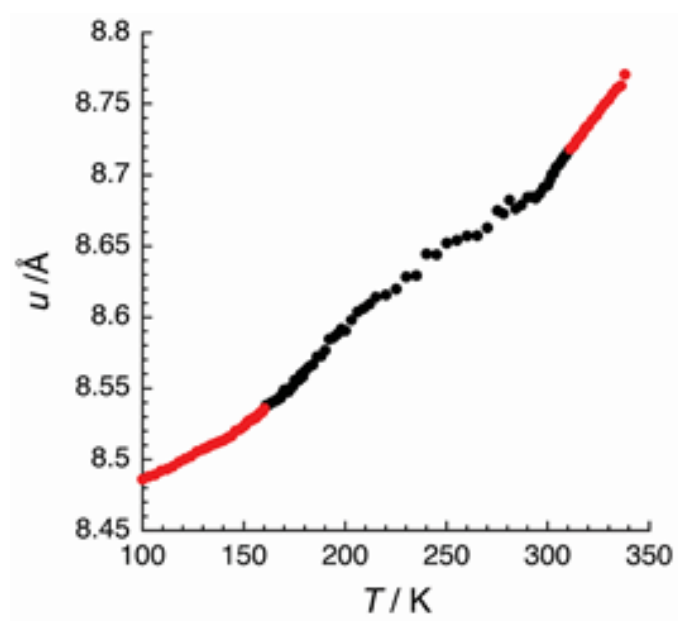

Figure 7. Temperature dependence of the average (in the triclinic phase, in black) or exact distance (in the monoclinic phases, in red) between two $\mathrm{La}(\mathrm{hfac})_{3}(\mathrm{pyDTDA})_{2}$ complexes along the supramolecular chain shown in Figure 3.

To describe a structural distortion, two competing free energy terms are required. In line with models describing similar phenomena, such as a spin-Peierls distortion, ${ }^{70}$ it is reasonable to invoke a magnetic term, which favors the distortion (i.e., the triclinic phase), and an elastic term, which is the lattice contribution and is minimized for the higher symmetry (i.e., monoclinic) phase. The lattice term for the free energy is simply given by Equation 1, where $N$ is the number of $[\mathrm{pyDTDA}]_{2}$ dimers, $\kappa$ is some force constant associated with the rigidity of the lattice, while $u_{1}, u_{2}$, and $\delta u=\left(u_{1}-u_{2}\right) / 2$ describe displacement (i.e., position) in one dimension.

$\delta F_{\text {lat }} \approx N \frac{\kappa}{2}\left(\frac{u_{1}-u_{2}}{2}\right)^{2}=N \frac{\kappa}{2} \delta u^{2} \quad$ Eq. 1

Indeed, Equation 1 is equivalent to Hooke's law. More specifically in the present case, $u_{1}$ and $u_{2}$ are the distances between two neighboring $\mathrm{La}(\mathrm{hfac})_{3}(\mathrm{pyDTDA})_{2}$ complexes along the chain. In the monoclinic phases, when all the [pyDTDA $]_{2}$ dimers are of the same type, $u_{1}=u_{2}$ and $\delta u=0$, minimizing the elastic contribution. In the triclinic phase, there are two types of [pyDTDA $]_{2}$ dimer, "closed" and "open”, so $u_{1}$ $\neq u_{2}$ and $\delta u^{2}>0$.

The magnetic term, $F_{\text {mag }}$, arises from the pyDTDA radical ligands. The simplest assumption is that each [pyDTDA $]_{2}$ dimer is magnetically isolated from all other [pyDTDA $]_{2}$ dimers. Thus, only the exchange coupling between the two spins in an isolated [pyDTDA] $]_{2}$ dimer needs to be accounted for, and any exchange between dimers will be neglected. This assumption implies that the "collective three-dimensional effect" required to produce a phase transition is transmitted by the lattice, meaning that there is a large free energy term that determines the mean unit cell parameter and its temperature dependence (vide supra). For a microscopic model, it is only necessary to describe the possibility of a distortion (lowering of symmetry) from the uniform configuration of higher symmetry. For $N$ noninteracting [pyDTDA] $]_{2}$ dimers in the monoclinic phases, there is only one energy gap, $\Delta=|2 J|$, (between the singlet ground state and the triplet excited state) associated with the exchange interaction, $J$ (defined by $\mathbf{H}=-$ $2 J S_{1} S_{2}$ ), between $S_{\mathrm{i}}=1 / 2$ spins. As the triplet state is triply degenerate, the magnetic free energy is given by Equation 2 .

$F_{0}(T, \Delta)=-k_{B} T N \ln \left(1+3 e^{-\Delta / k_{B} T}\right) \quad$ Eq. 2

In the triclinic phase, two kinds of [pyDTDA $]_{2}$ dimers ("closed" and "open") are observed (vide supra) inducing the presence of two different energy gaps, $\Delta_{1}$ and $\Delta_{2}$. In this low symmetry phase, the magnetic free energy is then given by Equation 3.

$$
\begin{aligned}
& F_{\text {mag }} \\
& \qquad \begin{aligned}
= & -k_{B} T \frac{N}{2} \ln \left(1+3 e^{-\Delta_{1} / k_{B} T}\right) \\
& -k_{B} T \frac{N}{2} \ln \left(1+3 e^{-\Delta_{2} / k_{B} T}\right)
\end{aligned}
\end{aligned}
$$

Eq. 3

Assuming that the difference between the two energy gaps is small, the expression of $F_{\text {mag }}$ can be developed further by introducing the mean energy gap, $\Delta=\left(\Delta_{1}+\Delta_{2}\right) / 2$, and the deviation from this average value, $\delta \Delta=\left(\Delta_{1}-\Delta_{2}\right) / 2$. Including up to second order terms, Equation 3 can be rewritten as shown in Equation 4. 


$$
\begin{aligned}
F_{\text {mag }} & =\frac{1}{2}\left(F_{0}(T, \Delta+\delta \Delta)+F_{0}(T, \Delta-\delta \Delta)\right) \\
& =F_{0}(T, \Delta)+\delta F_{\text {mag }}(T, \Delta)
\end{aligned}
$$

with

$$
\begin{aligned}
& \delta F_{\text {mag }}(T, \Delta) \approx \frac{1}{2} F^{\prime \prime}{ }_{0}(T, \Delta) \delta \Delta^{2} \\
& \approx-\frac{3 N}{2 k_{\mathrm{B}} T} \frac{e^{\Delta / k_{B} T}}{\left(e^{\Delta / k_{B} T}+3\right)^{2}} \delta \Delta^{2}
\end{aligned}
$$

The total free energy, $\delta F$ (taking the origin of the free energy in the monoclinic phase), is then the sum of the magnetic and lattice free energy terms (calculated at the second order), $\delta F=\delta F_{\text {mag }}+\delta F_{\text {lat, }}$, given by Equation 6 (with $\delta \Delta=(\mathrm{d} \Delta / \mathrm{d} u) \delta u=\alpha \delta u$; see the Supporting Information).

$$
\begin{aligned}
& \frac{\delta F}{N}=\left(\kappa-\frac{3 \alpha^{2}}{k_{B} T} \frac{e^{\Delta / k_{B} T}}{\left(e^{\Delta / k_{B} T}+3\right)^{2}}\right) \frac{\delta u^{2}}{2} \\
& =(\kappa-A(T)) \frac{\delta u^{2}}{2}
\end{aligned}
$$

As the magnetic contribution, $\delta F_{\text {mag }}$, to the free energy is always negative (Equation 5), it naturally favors the triclinic phase (i.e. two different [pyDTDA $]_{2}$ dimers), while the elastic term, $\delta F_{\text {lat }}$, is always positive (Equation 1), stabilizing the monoclinic phase. In Equation 6, the elastic and magnetic terms, $\kappa$ and $A(T)$, are in competition, with an instability for $\kappa$ $=A\left(T_{\mathrm{C}}\right)$ and thus the possibility of phase transitions.

In order to demonstrate that this microscopic model correctly describes the present system with its two successive phase transitions at 163 and $312 \mathrm{~K}$, it is crucial to estimate experimentally the $A(T)$ term that is a function of $\Delta(T)$ and $\alpha=$ $d \Delta / d u$ (Equation 6). While the structural data shown in Figure 7 allow an estimation of $u(T)$, the magnetic properties of $\mathrm{La}(\mathrm{hfac})_{3}(\text { pyDTDA })_{2}$ (i.e., $\chi T$ vs. $T$ data, Figure 6), give access to the temperature dependence of the energy gap, $\Delta(T)$. To employ the measured magnetic data, the non-zero value of the $\chi T$ product below $75 \mathrm{~K}\left(\chi T_{\mathrm{LT}}=0.036 \mathrm{~cm}^{3} \mathrm{Kmol}^{-1}\right)$ must be taken into account. To simplify the subsequent calculation, the $\chi T$ product has been normalized between 0 and 1 using the following expression, $\chi_{n} T=\left(\chi T-\chi T_{\mathrm{LT}}\right) /\left(2 C_{1 / 2}-\chi T_{\mathrm{LT}}\right)$ with $C_{1 / 2}=$ $g^{2} N \mu_{\mathrm{B}}{ }^{2} / 4 k_{\mathrm{B}}$ being the Curie constant for an $S=1 / 2$ spin (with $g$ $=2$ expected for radicals, $C_{1 / 2}=0.375 \mathrm{~cm}^{3} \mathrm{Kmol}^{-1}$ ). In the monoclinic phase, there is only one energy gap, $\Delta$, that is related to the $\chi_{n} T$ product by the normalized Bleaney-Bowers equation (Equation 7). ${ }^{71,72}$ The temperature dependence of the energy gap (Equation 8 and Figure 8) is thus obtained from Equation 7.

$$
\begin{array}{ll}
\chi_{n} T=\frac{4}{e^{\Delta / k_{\mathrm{B}} T}+3} & \text { Eq. } 7 \\
\Delta(T)=k_{\mathrm{B}} T \ln \left(\frac{4}{\chi_{n} T}-3\right) & \text { Eq. } 8
\end{array}
$$

Two points are worth noting. First, in the triclinic phase (gray symbols in Figure 8), the estimated $\Delta(T)$ is only an effective gap (i.e. different from $\left(\Delta_{1}+\Delta_{2}\right) / 2$ ) due to the presence of the two different [pyDTDA $]_{2}$ dimers, and second, $\chi_{n}$ is not a linear function of $\Delta$. Therefore the average energy gap, $\left(\Delta_{1}+\Delta_{2}\right) / 2$, (and thus $d \Delta d T$ ) can not be estimated in the triclinic phase from the magnetic data.

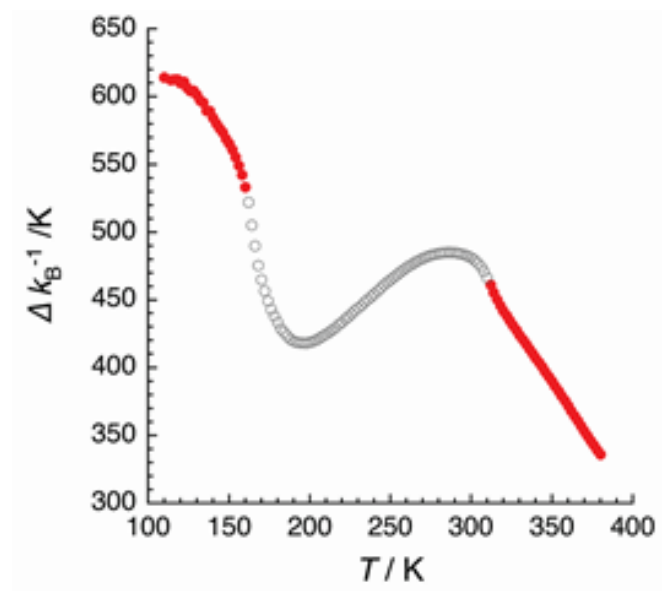

Figure 8. Effective singlet-triplet energy gap, $\Delta(T)$, derived from the measured magnetic data (Figure 6) as described in the text (Equation 8), is plotted as a function of temperature; (red) monoclinic phases; (gray) triclinic phase. Data below $100 \mathrm{~K}$ are not plotted as the experimental $\chi T$ values (Figure 6) become too small for an accurate determination of the gap.

Considering the temperature dependence of $\Delta(T)$, and $u(T)$ in the monoclinic phases (red data points in Figures 7 and 8), $d \Delta d T$ and $d u / d T$ can be calculated, and their ratio $(d \Delta / d u)$ can be used to determine $\alpha(T)$, as demonstrated in the Supporting Information, and then $A(T)$ (vide supra, Equation 6). As shown in Figure 9, the magnetic term, $A(T)$, increases up to $163 \mathrm{~K}$ and decreases above $312 \mathrm{~K}$. As demonstrated by Equation 6, the monoclinic-triclinic phase transition occurs for $A\left(T_{C}\right)=\kappa$. The solid horizontal line in Figure 9 indicates the specific $A\left(T_{C}\right)=\kappa$ value that implies theoretical transition temperatures of $T_{\mathrm{C} 1}=160 \mathrm{~K}$ and $T_{\mathrm{C} 2}=310 \mathrm{~K}$. Supporting the consistency of the microscopic model, these critical temperatures are very close to the experimental ones $(163,312 \mathrm{~K})$ obtained from magnetic measurements (Figure 6). Between 160 and $310 \mathrm{~K}$, the instability of the monoclinic phase is clearly induced by the magnetic term as it becomes large in comparison to the elastic contribution of the network $(A(T)>\kappa)$, and thus this simple model automatically describes re-entrant phase transition behavior.

Comparing the experimental data and the microscopic model, $\kappa / k_{\mathrm{B}}$ can be estimated at about $2000 \mathrm{~K} \AA^{-2}$ (Figure 9) which corresponds to a frequency $\left(\Omega_{0}\right)$ of about $2.6 \mathrm{THz}$ or $\hbar \Omega_{0} / k_{\mathrm{B}}=20 \mathrm{~K}\left(\kappa=m \Omega_{0}{ }^{2}\right.$, with $m$ being the reduced mass of the oscillating dimer, ${ }^{73}$ i.e., the mass of a half pyDTDA radical). The $\Omega_{0}$ obtained for $\mathrm{La}(\mathrm{hfac})_{3}(\text { (pyDTDA })_{2}$ is comparable to frequencies reported for Spin-Peierls systems, ${ }^{74}$ which apparently have more rigid networks with $\hbar \Omega_{0} / k_{\mathrm{B}}$ values above $50 \mathrm{~K}$ (estimated for $(\mathrm{BCPTTF})_{2} \mathrm{PF}_{6},{ }^{75} \mathrm{BCPTTF}=$ benzocyclopentyl-tetrathiafulvalene). This comparison highlights that the key ingredient to obtain a phase transition sequence with a re-entrant phase is the weak rigidity of the network that allows the magnetic term to overcome the elastic 
contribution and thus to stabilize the low symmetry phase in a confined temperature domain.

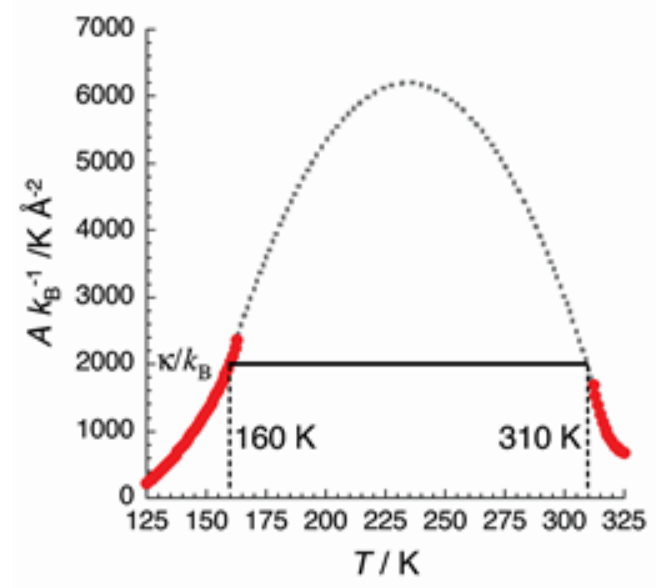

Figure 9. Temperature dependence of the $A(T)$ magnetic term of the free energy per $\mathrm{La}[\mathrm{pyDTDA}]_{2}$ unit is plotted for the monoclinic phase (red). Horizontal black line: visual guide at $A\left(T_{C}\right)=\kappa$ representing the boundary between the monoclinic and triclinic phases that best corresponds to the experimental data. Dashed line: parabolic extrapolation of $A(T)$ in the triclinic phase deduced from the analysis of the X-ray diffraction data shown in Figure 10.
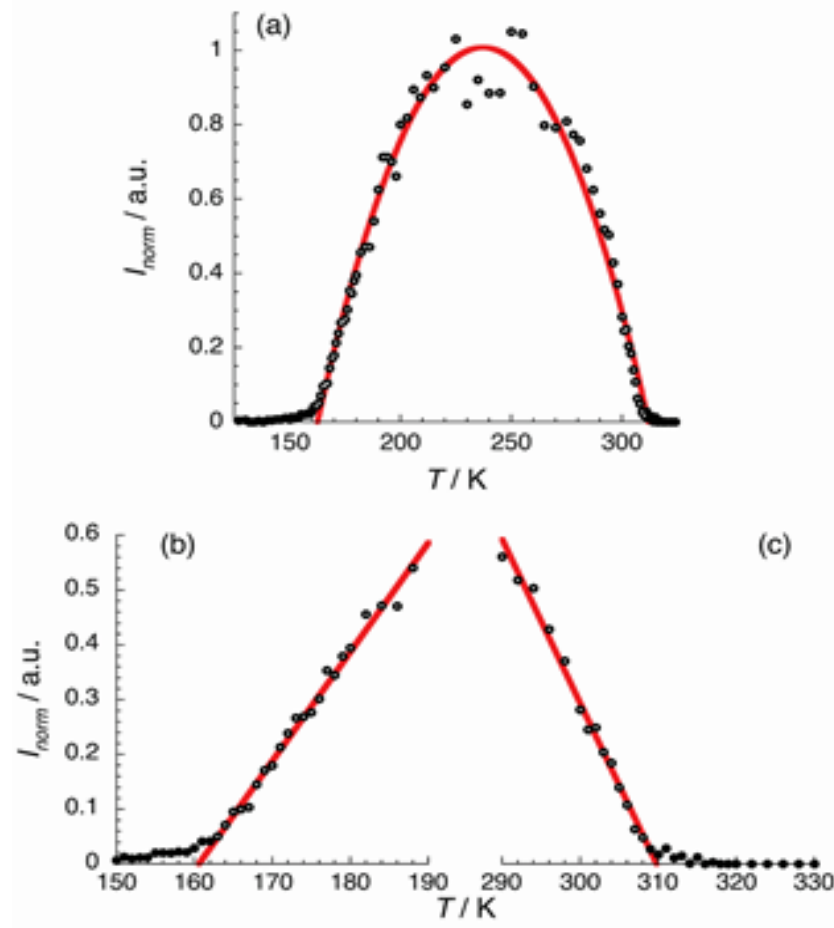

Figure 10. Temperature dependence of the intensity of the triclinic (0 5 -6) X-ray diffraction peak. (a) Red line: fit of the experimental points (black circles) to the parabolic function $I_{\mathrm{n}}(T-$ $\left.T_{\mathrm{C} 1}\right)\left(T_{\mathrm{C} 2}-T\right), I_{\mathrm{n}}$ being a constant. (b, c) Details of the main figure close to $T_{\mathrm{C} 1}$ and $T_{\mathrm{C} 2}$ in order to emphasize the continuous and linear temperature dependence (red line) near the critical temperatures, and thus the second order nature of the phase transitions.
In the triclinic phase, the order parameter associated with the phase transitions can be deduced experimentally from single-crystal X-ray diffraction data. Indeed, the intensity of the triclinic reflections (forbidden by symmetry in the monoclinic space group; Figure 4) is directly proportional to the square of this order parameter. ${ }^{76,77}$ Therefore the normalized intensity of the (0 5 -6) reflection, $I_{\text {norm, was }}$ measured between 100 and $338 \mathrm{~K}$ from 217 data sets as shown in Figure 10a. Similar temperature dependences have also been measured for other reflections and no significant difference on the intensities has been observed on cooling or heating mode (in agreement with the magnetic measurements; vide supra). The thermal variation of $I_{\text {norm }}$ is progressive and linear above $T_{\mathrm{C} 1} \approx 160 \mathrm{~K}$ and below $T_{\mathrm{C} 2} \approx 310 \mathrm{~K}$ in the triclinic phase (Figures 10b and 10c) supporting the presence of two second order phase transitions between triclinic and monoclinic phases. ${ }^{78}$ It is worth mentioning that the estimation of the critical temperatures from the $I_{\text {norm }}(T)$ data (Figure 10) agrees very well with the magnetic measurements (163 and 312 K; Figure 6).

In the triclinic phase, the reflection intensity exhibits a maximum around $236 \mathrm{~K}$ that almost perfectly matches the $\left(T_{\mathrm{C} 1}\right.$ $\left.+T_{\mathrm{C} 2}\right) / 2$ value, suggesting a simple parabolic behavior of $I_{\text {norm }}(T) \propto\left(T-T_{\mathrm{C} 1}\right)\left(T_{\mathrm{C} 2}-T\right)$. As expected, the fit of the experimental data (red line, Figure 10a) to this parabolic function is remarkably good with $T_{\mathrm{C} 1}=162 \mathrm{~K}$ and below $T_{\mathrm{C} 2}=$ $312 \mathrm{~K}$. As $I_{\text {norm }}$ is proportional to the square of the order parameter, the temperature dependence of the order parameter must be proportional to $\sqrt{\left(T-T_{C 1}\right)\left(T_{C 2}-T\right)}$.

As $\delta u=0$ and $\delta u \neq 0$ in the monoclinic and triclinic phase respectively, this parameter can be used as the order parameter associated with the transitions. Therefore the microscopic model of the free energy discussed in the monoclinic phase can be implemented to describe the theoretical temperature dependence of the order parameter in the triclinic phase and to compare with the above conclusions derived from singlecrystal X-ray diffraction data (Figure 10$)$. Because the $(\kappa-$ $A(T)$ ) term in Equation 6 becomes negative in the triclinic phase, this free energy needs to be developed at least to the $4^{\text {th }}$ order (Equation 9) in order to compensate for the effect of the second order term and to be able to estimate the $\delta u$ equilibrium value (noted $\overline{\delta u})$ of the system $(d \delta F / d \delta u=0)$.

$\frac{\delta F}{N}=(\kappa-A(T)) \frac{\delta u^{2}}{2}+B \frac{\delta u^{4}}{4}$

It is reasonable to expect that the coefficient $B$ of the fourthorder term in Equation 9 is dominated by lattice effects; therefore $B$ can be considered as temperature independent, to a first approximation. The minimization of the above free energy $(d \delta F / d \delta u=0)$ gives $\overline{\delta u}$ that is proportional to $\sqrt{A(T)-\kappa}$ (Equation 10).

$\overline{\delta u}(T)=\sqrt{\frac{A(T)-\kappa}{B}}$

To be consistent with the experimental data and the predicted $\sqrt{\left(T-T_{C 1}\right)\left(T_{C 2}-T\right)}$ dependence of the order parameter, Equation 10 implies that $A(T)$ also has a parabolic variation in the triclinic phase (Equation 11).

$A(T)-\kappa \propto\left(T-T_{C 1}\right)\left(T_{C 2}-T\right)$

Eq. 11 
When the following parameters are fixed to the previously estimated values, $\kappa / k_{\mathrm{B}}=2000 \mathrm{~K} \AA^{-2}, T_{\mathrm{C} 1} \approx 160 \mathrm{~K}$ and $T_{\mathrm{C} 2} \approx$ $310 \mathrm{~K}$, a very consistent prediction of $A(T)$ is obtained in the triclinic phase, as shown by the dotted gray line in Figure 9. This final demonstration confirms the full consistency of the microscopic model developed in this work to analyze in detail the re-entrant phase transition behavior observed in this La(hfac) $)_{3}$ (pyDTDA $)_{2}$ compound.

\section{Conclusions}

$\mathrm{La}(\mathrm{hfac})_{3}(\text { pyDTDA })_{2}$ is a 10 -coordinate complex in which the diamagnetic $\mathrm{La}$ (III) ion bridges two neutral radical pyDTDA ligands. In the solid state, this species exhibits unusual magnetic behavior. From a diamagnetic state below $80 \mathrm{~K}$, a sigmoidal-shape feature in the $\chi T(T)$ value appears with increasing temperature, followed by a small plateau and a second such sigmoidal-shape feature. Similar magnetic behavior is most commonly associated with two-step spincrossover in polynuclear spin-crossover species. ${ }^{79-82}$ In the present case, however, the origin of the phenomenon is two sequential structural phase transitions involving the rupture, or "opening", of so-called "pancake bonded" $\pi$-dimers of the radical ligands, [pyDTDA $]_{2}$. At low temperature, all the pyDTDA ligands participate in the formation of diamagnetic "closed" [pyDTDA $]_{2}$ dimers. Upon heating, the first phase transition occurs when $50 \%$ of the [pyDTDA] $]_{2}$ dimers are ruptured resulting in a magnetic moment consistent with one unpaired electron per molecule. The second phase transition occurs with the rupture of the remaining [pyDTDA $]_{2}$ dimers, and a concurrent increase in the measured magnetic moment. The phase transitions are accompanied by an alteration of the crystallographic space group from $C 2 / c$ to $P-1$ and back to $C 2 / c$. A microscopic free energy model, using elastic (lattice) and magnetic (radical-radical) contributions as the only two necessary physical components, is developed. Applying this model, it becomes immediately evident that the observed properties of $\mathrm{La}(\mathrm{hfac})_{3}(\mathrm{pyDTDA})_{2}$ are consistent with a rare case of a re-entrant phase diagram, meaning that the low temperature monoclinic phase is the same as the high temperature monoclinic phase, and encompassed between these is a temperature domain for which the lower symmetry triclinic phase is stabilized.

The intimate mechanism of the re-entrant phase transition, involving the rupture of "pancake bonds" between $\pi$-radicals, is entirely novel, as is the microscopic model that quantitatively describes the system. Our theoretical approach demonstrates the possible competition between a magnetic term ( $A$, related to the singlet-triplet energy difference) intrinsic to the radical pairs that form the "pancake bonds" and an elastic term $(\kappa)$ representing the flexibility of the network in which the radical pairs are organized. The re-entrant phenomenon is induced by the unusual softness of the network (small values for $\kappa$ ) allowing the magnetic term to dominate on a temperature domain for which a low symmetry (triclinic, in this case) re-entrant phase is stabilized. Thus, this microscopic model analyses the experimental data, but more importantly, it gives a general prediction for a re-entrant instability in a soft solid incorporating isolated "dimers". Accordingly, work is currently in progress in our laboratories to modulate the rigidity of the network $(\kappa)$ and the strength of the "pancake bonds" (A) by replacing the $\mathrm{La}(\mathrm{III})$ ion with other lanthanide ions in order to alter the transition temperatures of this unique system.

\section{ASSOCIATED CONTENT}

Supporting Information. Supplementary crystal structure data in CIF format; Table S1 containing structural and refinement data for single crystal structures at $100 \mathrm{~K}, 220 \mathrm{~K}$ and $340 \mathrm{~K}$; reflectance spectroscopy experimental, data, and discussion; analysis of the effective gap $\Delta$ close to the triclinic phase (black part of the curve in Figure 7); determination of $\alpha$; calorimetric study experimental, data, and discussion. This material is available free of charge on the ACS Publications website at DOI: 10.1021/acs.chemmater.5b00967.

\section{AUTHOR INFORMATION}

\section{Corresponding Authors}

*kpreuss@uoguelph.ca; clerac@crpp-bordeaux.cnrs.fr; coulon@crpp-bordeaux.cnrs.fr

\section{ACKNOWLEDGMENT}

K.E.P. acknowledges the Natural Sciences and Engineering Research Council (NSERC) of Canada for a Discovery Grant (DG), the government of Canada for a Tier II Canada Research Chair (Chemistry of Molecular Materials), the College of Physical and Engineering Sciences at U. Guelph for Graduate Growth funding and the University of Bordeaux for a visiting professorship. E.M.F. thanks NSERC for a CGS-D scholarship. D.V.S. thanks Canada Foundation for Innovation (CFI) for funding the X-ray diffraction facility. The work in France was supported by the University of Bordeaux, ANR, IUF, the Région Aquitaine, the GDR MCM2 and CNRS. The authors thank D. Mitcov for technical help and J.-P. Pouget for fruitful discussions.

\section{ABBREVIATIONS}

DTDA, 1,2,3,5-dithiadiazolyl; pyDTDA, 4-(2'-pyridyl)-1,2,3,5dithiadiazolyl; hfac, 1,1,1,5,5,5-hexafluoroacetylacetonato-; SOMO, singly occupied molecular orbital.

\section{REFERENCES}

(1) Aakeröy, C. B.; Seddon, K. R. Chem. Soc. Rev. 1993, 22, 397407.

(2) Aakeröy, C. B.; Salmon, D. J. CrystEngComm 2005, 7, 439448.

(3) Cui, Z.-h.; Lischka, H.; Beneberu, H. Z.; Kertesz, M. J. Am. Chem. Soc. 2014, 136, 12958-12965.

(4) Devic, T.; Yuan, M.; Adams, J.; Fredrickson, S. L.; Venkataraman, D. J. Am. Chem. Soc. 2005, 127, 14616-14627.

(5) Trabolsi, A.; Khashab, N.; Farenbach, A. C.; Friedman, D. C.; Colvin, M. T.; Coti, K. K.; Benítez, D.; Tkatchouk, E.; Olsen, J.-C.; Belowich, M. E.; Carmielli, R.; Khatib, H. A.; Goddard, III, W. A.; Wasielewski, M. R.; Stoddart, J. F. Nat. Chem. 2010, 2, 42-49.

(6) Capdevila-Cortada, M.; Novoa, J. J. Chem.-Eur. J. 2012, 18, 5335-5344.

(7) Tateno, M.; Takase, M.; Iyoda, M.; Komatsu, K.; Nishinaga, T. Chem.-Eur. J. 2013, 19, 5457-5467.

(8) Fairhurst, S. A.; Johnson, K. M.; Sutcliffe, L. H.; Preston, K. F.; Banister, A. J.; Hauptman, Z. V.; Passmore, J. J. Chem. Soc., Dalton Trans. 1986, 1465-1472.

(9) Cui, Z.-h.; Lischka, H.; Beneberu, H. Z.; Kertesz, M. J. Am. Chem. Soc. 2014, 136, 5539-5542.

(10) Haynes, D. A. CrystEngComm. 2011, 13, 4793-4798.

(11) Wang, Y.; Frasconi, M.; Liu, W.-G.; Sarjeant, A. A.; Nassar, M. S.; Botros, Y. Y.; Goddard, III, W. A.; Stoddart, J. F. J. Am. Chem. Soc. 2015, 137, 876-885. 
(12) Bruns, C. J.; Frasconi, M.; Iehl, J.; Hartlieb, K. J.; Schneebeli, S. T.; Cheng, C.; Stupp, S. I.; Stoddart, J. F. J. Am. Chem. Soc. 2014 136, 4714-4723.

(13) Suzuki, S.; Morita, Y.; Fukui, K.; Sato, K.; Shiomi, D.; Takui, T.; Nakasuji, K. J. Am. Chem. Soc. 2006, 128, 2530-2531.

(14) Beneberu, H. Z.; Tian, Y.-H.; Kertesz, M. Phys. Chem. Chem. Phys. 2012, 14, 10713-10725.

(15) Preuss, K. E. Polyhedron 2014, 79, 1-15.

(16) Hearns, N. G. R.; Fatila, E. M.; Clérac, R.; Jennings, M.; Preuss, K. E. Inorg. Chem. 2008, 47, 10330-10341.

(17) Britten, J.; Hearns, N. G. R.; Preuss, K. E.; Richardson, J. F.; Bin-Salamon, S. Inorg. Chem. 2007, 46, 3934-3945.

(18) Hearns, N. G. R.; Preuss, K. E.; Richardson, J. F.; BinSalamon, S. J. Am. Chem. Soc. 2004, 126, 9942-9943.

(19) SAINT, v8.27B; Bruker AXS: Madison, WI, 2012.

(20) SADABS, 2012/1; Bruker AXS: Madison, WI, 2012.

(21) Sheldrick, G. M. Acta Crystallogr., Sect. A. 2008, 64, 112122

(22) CrysAlis PRO; Agilent Technologies: Oxfordshire, U.K., 2011.

(23) Vegas, A.; Pérez-Salazar, A.; Banister, A. J.; Hey, R. G. J. Chem. Soc., Dalton Trans. 1980, 1812-1815.

(24) Clarke, C. S.; Haynes, D. A.; Smith, J. N. B.; Batsanov, A. S.; Howard, J. A. K.; Pascu, S. I.; Rawson, J. M. CrystEngComm. 2010, $12,172$.

(25) Banister, A. J.; Smith, N. R. M.; Hey, R. G. J. Chem. Soc., Perkin Trans. 1 1983, 1181-1186.

(26) Shuvaev, K. V.; Decken, A.; Grein, F.; Abedin, T. S. M.; Thompson, L. K.; Passmore, J. Dalton Trans. 2008, 4029-4037.

(27) Banister, A. J.; Bricklebank, N.; Lavender, I.; Rawson, J. M.; Gregory, C. I.; Tanner, B. K.; Clegg, W.; Elsegood, M. R. J.; Palacio, F. Angew. Chem., Int. Ed. 1996, 35, 2533-2535.

(28) Alberola, A.; Less, R. J.; Pask, C. M.; Rawson, J. M.; Palacio, F.; Oliete, P.; Paulsen, C.; Yamaguchi, A.; Farley, R. D.; Murphy, D. M. Angew. Chem., Int. Ed. 2003, 42, 4782-4785.

(29) Alberola, A.; Clarke, C. S.; Haynes, D. A.; Pascu, S. I.; Rawson, J. M. Chem. Commun. 2005, 4726-4728.

(30) Fatila, E. M.; Jennings, M. C.; Goodreid, J.; Preuss, K. E. Acta Crystallogr., Sect. C 2010, 66, O260-O264.

(31) Frisch, M. J.; Trucks, G. W.; Schlegel, H. B.; Scuseria, G. E.; Robb, M. A.; Cheeseman, J. R.; Scalmani, G.; Barone, V.; Mennucci, B.; Petersson, G. A.; Nakatsuji, H.; Caricato, M.; Li, X.; Hratchian, H. P.; Izmaylov, A. F.; Bloino, J.; Zheng, G.; Sonnenberg, J. L.; Hada, M.; Ehara, M.; Toyota, K.; Fukuda, R.; Hasegawa, J.; Ishida, M.; Nakajima, T.; Honda, Y.; Kitao, O.; Nakai, H.; Vreven, T.; Montgomery, J. A. Jr.; Peralta, J. E.; Ogliaro, F.; Bearpark, M.; Heyd, J. J.; Brothers, E.; Kudin, K. N.; Staroverov, V. N.; Kobayashi, R.; Normand, J.; Raghavachari, K.; Rendell, A.; Burant, J. C.;. Iyengar, S. S; Tomasi, J.; Cossi, M.; Rega, N.; Millam, J. M.; Klene, M.; Knox, J. E.; Cross, J. B.; Bakken, V.; Adamo, C.; Jaramillo, J.; Gomperts, R.; Stratmann, R. E.; Yazyev, O.; Austin, A. J.; Cammi, R.; Pomelli, C.; Ochterski, J. W.; Martin, R. L.; Morokuma, K.; Zakrzewski, V. G.; Voth, G. A.; Salvador, P.; Dannenberg, J. J.; Dapprich, S.; Daniels, A. D.; Farkas, O.; Foresman, J. B.; Ortiz, J. V.; Cioslowski, J.; Fox, D. J. Gaussian 09, Revision A.02; Gaussian Inc.: Wallingford, CT 2009.

(32) Dennington, R.; Keith, T.; Millam, J. GaussView, version 5; Semichem: Shawnee, KS, 2009.

(33) Chaikin, P. M.; Lubensky, T. C. In Principles of Condensed Matter Physics; Cambridge University Press: Cambridge, U.K., 1995; p 10-15.

(34) Fatila, E. M.; Hetherington, E. E.; Jennings, M.; Lough, A. J.; Preuss, K. E. Dalton Trans. 2012, 41, 1352-1362.

(35) Barclay, T. M.; Cordes, A. W.; George, N. A.; Haddon, R. C.; Itkis, M. E.; Oakley, R. T. Chem. Commun. 1999, 2269-2270.

(36) Brusso, J. L.; Clements, O. P.; Haddon, R. C.; Itkis, M. E.; Leitch, A. A.; Oakley, R. T.; Reed, R. W.; Richardson, J. F. J. Am. Chem. Soc. 2004, 126, 8256-8265.

(37) Awaga, K.; Tanaka, T.; Shirai, T.; Fujimori, M.; Suzuki, Y.; Yoshikawa, H.; Fujita, W. Bull. Chem. Soc. Jpn. 2006, 79, 25-34.
(38) Clarke, C. S.; Jornet, J.; Deumal, M.; Novoa, J. J. Polyhedron 2009, 28, 1614-1619.

(39) Clarke, C. S.; Jornet-Somoza, J.; Mota, F.; Novoa, J. J.; Deumal, M. J. Am. Chem. Soc. 2010, 132, 17817-17830.

(40) Vela, S.; Mota, F.; Deumal, M.; Suizu, R.; Shuku, Y.; Mizuno, A.; Awaga, K.; Shiga, M.; Novoa, J. J.; Ribas-Arino, J. Nat. Commun. 2014, 5, DOI: $10.1038 /$ ncomms5411.

(41) Barclay, T. M.; Cordes, A. W.; George, N. A.; Haddon, R. C.; Itkis, M. E.; Mashuta, M. S.; Oakley, R. T.; Patenaude, G. W.; Reed, R. W.; Richardson, J. F.; Zhang, H. J. Am. Chem. Soc. 1998, 120, 352-360.

(42) Fujita, W.; Awaga, K. Science 1999, 286, 261-262.

(43) Brusso, J. L.; Clements, O. P.; Haddon, R. C.; Itkis, M. E.; Leitch, A. A.; Oakley, R. T.; Reed, R. W.; Richardson, J. F. J. Am. Chem. Soc. 2004, 126, 14692-14693.

(44) Rawson, J. M.; Hayward, J. J. In Spin-Crossover Materials: Properties and Applications, first ed.; Halcrow, M. A., Ed.; John Wiley \& Sons: Chichester, U.K., 2013; p 225-237.

(45) Schneider, H.-J. Chem. Sci. 2012, 3, 1381-1394.

(46) Gold, B.; Dudley, G. B.; Alabugin, I. V. J. Am. Chem. Soc. 2013, 135, 1558-1569.

(47) Struble, M. D.; Strull, J.; Patel, K.; Siegler, M. A.; Lectka, T. J. Org. Chem. 2014, 79, 1-6.

(48) Beekman, R.; Boeré, R. T.; Moock, K. H.; Parvez, M. Can. J. Chem. 1998, 76, 85-93.

(49) Bryan, C. D.; Cordes, A. W.; Haddon, R. C.; Hicks, R. G.; Oakley, R. T.; Palstra, T. T. M.; Perel, A. J. J. Chem. Soc., Chem. Commun. 1994, 1447-1448.

(50) Greer, A. L. Nature 2000, 404, 134-136.

(51) Portmann, O.; Vaterlaus, A.; Pescia, D. Nature 2003, 422, 698-701.

(52) Tammann, G. In Kristallisieren und Schmelzen; Johann Ambosius Barth: Leipzig, Germany, 1903; p 26-46.

(53) Rae, A. I. M.; Dove, M. T. J. Phys. C: Solid State Phys. 1983, $16,3233-3244$

(54) Cladis, P. E. Phys. Rev. Lett. 1975, 35, 48-51.

(55) Katayama, S.; Hirokawa, Y.; Tanaka, T. Macromolecules

1984, 17, 2641-2643.

(56) Narayanan, T.; Kumar, A. Phys. Rep. 1994, 249, 135-218.

(57) Naughton, M. J.; Chamberlin, R. V.; Yan, X.; Hsu, S.-Y.; Chiang, L. Y.; Azbel, M. Y.; Chaikin, P. M. Phys. Rev. Lett. 1988, 61, 621-624.

(58) Lin, T. H.; Shao, X. Y.; Wu, M. K.; Hor, P. H.; Jin, X. C.; Chu, C. W.; Evans, N.; Bayuzick, R. Phys. Rev. B 1984, 29, 14931496.

(59) Borycki, D.; Maćkowiak, J. Supercond. Sci. Technol. 2011, 24, 035007 (035013pp).

(60) Griffiths, R. B. In Critical Phenomena in Alloys, Magnets and Superconductors; Mills, R. E., Ascher, E., Jaffee, R. I., Eds.; Mcgraw-Hill: New York, 1971; p 377-388.

(61) Törnroos, K. W.; Hostettler, M.; Chernyshov, D.; Vangdal, B.; Bürgi, H.-B. Chem. Eur. J. 2006, 12, 6207-6215.

(62) Liu, J.; Harms, M.; Garamus, V. M.; Müller-Goymann, C. C. Soft Matter 2013, 9, 6371-6375.

(63) Lundegaard, L. F.; Stinton, G. W.; Zelazny, M.; Guillaume, C. L.; Proctor, J. E.; Loa, I.; Gregoryanz, E.; Nelmes, R. J.; McMahon, M. I. Phys. Rev. B 2013, 88, 054106(pp054106).

(64) Altamirano, N.; Kubizňák, D.; Mann, R. B. Phys. Rev. D 2013, 88, 101502(pp101505).

(65) Statistical Physics (Part 1): Landau and Lifshitz Course of Theoretical Physics; 3rd ed.; Lifshitz, E. M., Pitaevskii, L. P., Eds.; Permagon Press: Oxford, U.K., 1980; Vol. 5.

(66) Pershan, P. S.; Prost, J. J. Phys., Lett. 1979, 40, 27-30.

(67) Dove, M. T. Am. Mineral. 1997, 82, 213-244.

(68) Longa, L. J. Chem. Phys. 1986, 85, 2974-2985.

(69) In a triclinic unit cell, $\mu$ can be estimated from the following relation:

$$
\mu=\frac{1}{2} \sqrt{a^{2}+b^{2}+c^{2}+2 a b \cos (\gamma)+2 a c \cos (\beta)+2 b c \cos (\alpha)}
$$


(70) Cross, M.; Fisher, D. Phys. Rev. B 1979, 19, 402-419. 1986.

(71) Carlin, R. L. Magnetochemistry; Springer-Verlag: Berlin,

(72) Bleaney, B.; Bowers, K. D. Proc. R. Soc. London, Ser. A 1952, 214, 451-465.

(73) Chandler, D. In Introduction to Modern Statistical Mechanics; Oxford University Press: Oxford, U.K., 1987; p 109.

(74) Pouget, J.-P. Eur. Phys. J. B 2001, 20, 321-333.

(75) Ducasse, L.; Coulon, C.; Chasseau, D.; Yagbasan, R.; Fabre, J. M.; Gouasmia, A. K. Synth. Met. 1988, 27, B543-B548.

(76) Girault, S.; Moudden, A. H.; Pouget, J.-P. Phys. Rev. B 1989, 39, 4430-4434.

(77) Pouget, J.-P. In Low dimensional conductors and superconductors; Jérome, D., Caron, L. G., Eds.; NATO ASI Ser. B Plenum Press: New York, 1987; Vol. 155, p 17.
(78) Close to a second order phase transition and at the mean field approximation, the square of the order parameter varies linearly with $T-T_{\mathrm{C}},\left(T_{\mathrm{C}}\right.$ being the transition temperature).

(79) Köppen, H.; Müller, E. W.; Kóhler, C. P.; Spiering, H.; Meissner, E.; Gütlich, P. Chem. Phys. Lett. 1982, 91, 348-352.

(80) Real, J.-A.; Bolvin, H.; Bousseksou, A.; Dworkin, A.; Kahn, O.; Varret, F.; Zarembowith, J. J. Am. Chem. Soc. 1992, 114, 46504658.

(81) Bousseksou, A.; Nasser, J.; Linares, J.; Boukheddaden, K.; Varret, F. J. Phys. I 1992, 2, 1381-1403.

(82) Clérac, R.; Cotton, F. A.; Dunbar, K. R.; Lu, T.; Murillo, C. A.; Wang, X. J. Am. Chem. Soc. 2000, 122, 2272-2278. 
TOC graphic

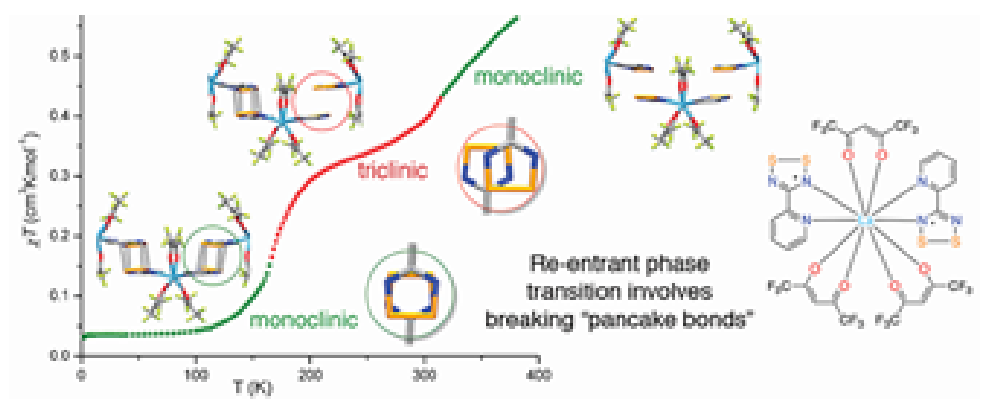

